\title{
A study on the relationship between religiosity and forgiveness among students
}

\begin{abstract}
The objective of the research is the determination of relationship between religiosity and forgiveness. This study is based on the description-correlation method. 148 students (61 females \& 63 males) were chosen through cluster, multi-staged and random sampling at the university. They filled out two questionnaires on religiosity, based on Glock-Stark model, and the tendency toward forgiveness. The data was analyzed via correlation coefficient and regression analysis. Between the variables of religiosity (ideological, ritual, experimental, and outcomes) and forgiveness, and its components (self, others, and situation), there is only forgiveness which has found no meaningful association with religious components. The results of regression analysis indicated that the total score of forgiveness and two subscales of forgiveness and forgiveness of situation have been predicted by the religious forgiveness. The results of the study are meant to confirm the findings which conceptualize forgiveness and religiosity as related constituents. These results are also useful for the experts who are looking for the patterns of preventing and treatment of mental and behavioral disorders.
\end{abstract}

Keyword: Relationship; Religiosity and forgiveness; Students 